\title{
Epistaxis and diabetes mellitus in an obese woman
}

\author{
Venkata Ranga Rao Kodali, Alexander Schmitz, Nigel Anthony Harrison
}

A 58-year-old woman presented as an emergency with profuse epistaxis. She had had a flu-like illness 2 weeks earlier and was taking aspirin. She had smoked 25 cigarettes/day for the last 20 years and had peripheral vascular disease, hypertension, ischaemic heart disease, chronic obstructive pulmonary disease and spinal stenosis. Medications on admission included bronchodilators and inhaled steroids.

On examination she was obese with Cushingoid features. Nicotine stains on the fingers, palmar erythema and oral thrush were obvious findings. Blood pressure was $110 / 66 \mathrm{mmHg}$, heart rate 100 beats/min. Respiratory system examination suggested consolidation in the right base. Systemic examination did not reveal further abnormalities. She was admitted for further observation to the medical ward after packing the nostrils.

The following blood results were abnormal on admission: glucose $18 \mathrm{mmol} / 1$ (normal range: 3.5-9), potassium $2.9 \mathrm{mmol} / 1$ (3.5-5.5), bicarbonate $34.7 \mathrm{mmol} / 1$ (22-32), alkaline phosphatase $350 \mathrm{IU} / 1$ (98-279), $\gamma$-glutamyl transferase $176 \mathrm{IU} / 1$ (7-33), and white cell count $17.8 \times 10^{9} / 1$ (4-10). Chest X-ray showed consolidation of right lower lobe. An electrocardiogram showed prominent $P$ waves and left ventricular hypertrophy with strain pattern. She received antibiotics, bronchodilators and insulin. Epistaxis was easily controlled. Over the following two weeks she developed weakness and worsening hypokalaemia. Further investigations were carried out, including computed tomography (CT) scans of the thorax and abdomen (figure).
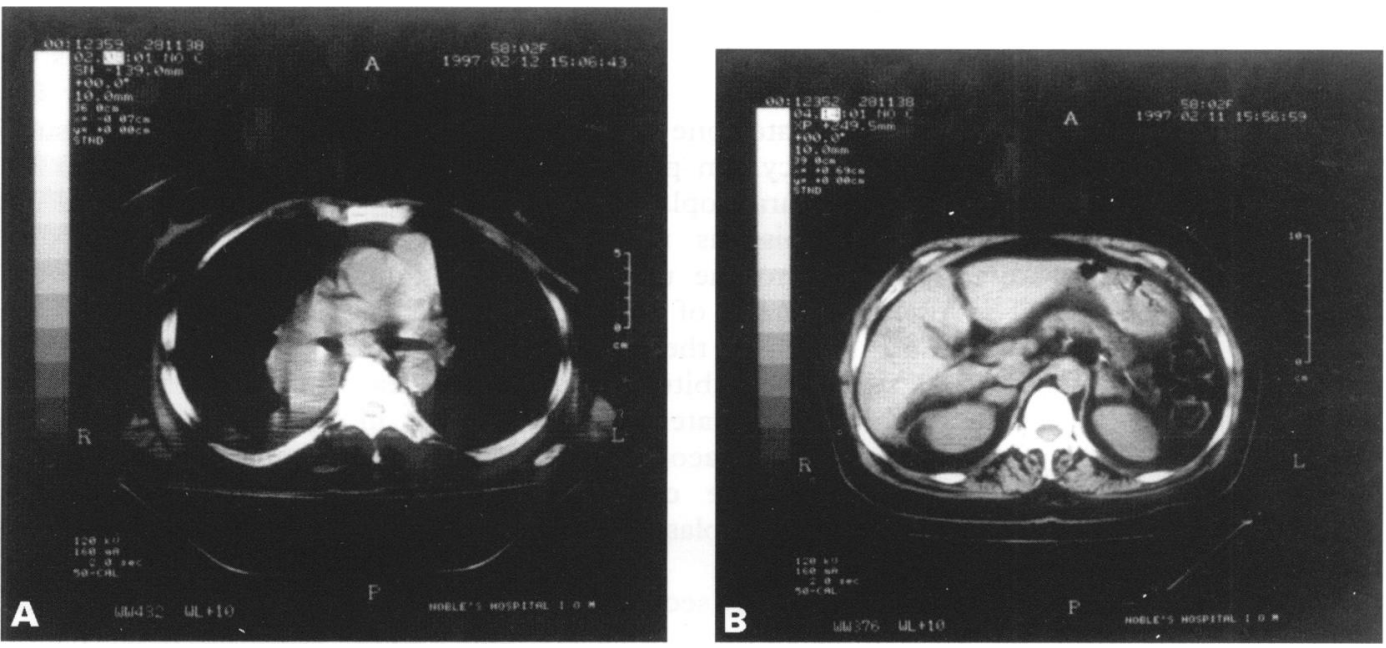

Medicine, Nobles Isle of Man Hospitals,

Westmoreland Road,

Douglas, Isle of Man,

IM1 4QA, UK

V R R Kodali

A Schmitz

N A Harrison

Correspondence to Dr VRR Kodali, Department of

Medicine, General Hospital Hartlepool TS24 9AH, UK

Accepted 21 January 1998 


\section{Answers}

QUESTION

CT scan of the abdomen shows bilateral adrenal hyperplasia. A low-density area is noted in the liver. On the chest CT scan, mediastinal lymphadenopathy and a mass behind the right main bronchus are seen.

QUESTION 2

Paraneoplastic Cushing's syndrome.

QUESTION 3

Measurement of serum cortisol levels and dexamethasone suppression test are indicated. The cortisol levels were as follows: $09.00 \mathrm{~h}$ : $3238 \mathrm{nmol} / \mathrm{l}$ (155-785), $24.00 \mathrm{h:} 3132 \mathrm{nmol} / \mathrm{l}$ (55-250); urinary cortisol $15268 \mathrm{nmol} / 24 \mathrm{~h}$ (190-880). Dexamethasone suppression test showed a baseline cortisol of 3320 and very little suppression (2875) after dexamethasone. Adrenocorticotropin (ACTH) concentration was $189 \mathrm{pmol} / \mathrm{l}(2-11.3)$. CT scan of the pituitary fossa was normal.

\section{QUESTION 4}

Management consists of nasal packing to achieve homeostasis, control of diabetes, correction of hypokalaemia and metyrapone to suppress the steroidogenesis. The prognosis is poor. Our patient died within 4 weeks of admission.

\section{Discussion}

This case illustrates one of the many ways in which malignancy can present, and the poor prognosis of paraneoplastic Cushing's syndrome. The epistaxis may not have been directly related to the underlying condition. The typical features of ectopic ACTH syndrome are shown in the box. Hirsutism and typical Cushingoid habitus are not regular features, although the later may be present in ACTH-secreting phaeochromocytomas and carcinoids when the course is slow. The circadian patterns of plasma ACTH and cortisol are lost.

ACTH is normally secreted by the pituitary and acts on the adrenal cortex to produce steroid hormones. When present in excess from this source, it causes Cushing's disease, while the endogenous Cushing's syndrome results from adrenal tumours and ectopic secretion of ACTH. The commonest cause of the ectopic ACTH syndrome is small cell lung cancer. The order of frequency for tumours commonly producing ACTH is lung cancer $(50 \%)$, thymomas $(10 \%)$, pancreatic cancer $(10 \%)$, medullary carcinoma of the thyroid $(5 \%)$, neural crest tumours $(5 \%)$, carcinoids (5\%), and bronchial adenomas $(2 \%){ }^{1}$

The precursor hormone of ACTH is known as propiocortin. Propiocortin is secreted in almost all types of lung cancers. The precursor is synthesized to a greater extent than the active hormone in ectopic production. In recent years, where their estimation is possible, the revised criteria in diagnosis are followed, ${ }^{23}$ with a ratio of the precursor to

\section{Common clinical findings and biochemistry of ectopic ACTH syndrome}

- oedema

- hypertension

- hyperpigmentation

- proximal muscle weakness

- psychosis

- hypokalaemic alkalosis

- secondary diabetes

- hypernatraemia

- high serum cortisol

- high urinary cortisol

- high serum ACTH

- lack of cortisol suppressibility on dexamethasone test

- elevated ACTH precursors

ACTH $\geqslant 48$ considered diagnostic. Radiological findings are adrenal hyperplasia and pulmonary shadows. Patients do not live long enough to develop nodular changes in the adrenals, so, if found, one should look for causes other than ectopic secretion or a conjectural association.

Cushing's disease should be differentiated from the syndrome. In one series, seven cases with ectopic ACTH syndrome were compared to 23 with Cushing's disease. ${ }^{2}$ The longer the duration of the illness, the more likely the diagnosis is Cushing's disease (12-72 months vs 2-12 months for Cushing's syndrome). The following results suggest Cushing's syndrome: plasma potassium $<3 \mathrm{mmol} / \mathrm{l}, 09.00 \mathrm{~h}$ plus midnight cortisol on dexamethasone $>450$ $\mathrm{nmol} / \mathrm{l}$ and urinary free cortisol $>1000 \mathrm{nmol} / \mathrm{l}$. Similar findings were also present in another study of ectopic Cushing's syndrome in lung cancer, where 22 of the 23 patients had hypokalaemic alkalosis and all patients had high urinary and plasma cortisol concentrations. ${ }^{4}$ Suspicion should be high in any patient presenting with hypokalaemic alkalosis for which another explanation is not readily available.

Medical treatment is aimed at blocking the synthesis of steroid hormones using aminoglutethimide, ketoconazole and metyrapone, but this may be only partially effective. Adrenal arterial embolisation using dura matter, alcohol and steel coils were all tried in an attempt to control the Cushing's syndrome. ${ }^{5}$ Octreotide and somatostatin analogues have not been found to be useful, ${ }^{67}$ and indeed paradoxical rises in ACTH and cortisol, and deterioration of the clinical state has been reported. ${ }^{7}$ The experience with ketoconazole is complex. It seems to improve the hormone profile but the suppression of hormone production can be so dramatic that subjects may require steroid supplements during intercurrent stress. ${ }^{8}$ Since the infective complications are high in ectopic ACTH syndrome, ${ }^{4}$ it should be used with caution. Medical management using enzyme inhibitors helps to alleviate symptoms and surgical adrenalectomy is attempted where possible. Except in adenoma, surgical removal of the 
tumour is unlikely to cure the Cushing's syndrome as these cases often present late. Considering the limited value of the therapeutic interventions, the prognosis, especially in ectopic ACTH syndrome associated with malignant tumours, is very poor, ${ }^{49}$ with a mean survival of 3 to 5 months.

1 Odell WD. Endocrine complications of cancer. In: Calabresi P, Schein PS, eds. Medical oncology, 2nd edn. New York: McGraw-Hill, Inc, 1993; pp172-83.

2 Blunt SB, Sandler LM, Burrin JM, Joplin GF. An evaluation of the distribution of ectopic and pituitary ACTH dependent Cushing's syndrome by clinical features, biochemical tests and radiological features. $Q 7 \mathrm{Med} 1990 ; 77: 1113-33$.

3 Stewart PM, Gibson S, Crosby SR, et al. ACTH precursors characterize the ectopic ACTH syndrome. Clin Endocrinol 1994;40:199-204.

4 Shepherd FA, Laskey J, Crump M, Goss PE, Johansen E, Khamsi F. Cushing's syndrome associated with ectopic production and small-cell lung cancer. $\mathcal{F}$ Clin Oncol 1992;10: 21-7.

5 Blunt SB, Pirmohamed M, Chatteriee VKK, Burrin JM, Allison DJ, Joplin GF. Use of adrenocortical embolisation in severe ACTH-dependent Cushing's syndrome. Postgrad Med f 1989;65:575-9.

\section{Final diagnosis}

Ectopic ACTH syndrome secondary to lung cancer and secondary diabetes mellitus.

Keywords: Cushing's syndrome; diabetes mellitus; ectopic ACTH syndrome; epistaxis; lung cancer

6 Cheung NW, Boyages SC. Failure of somatostatin analogue to control Cushing's syndrome in two cases of ACTH producing carcinoid tumors. Clin Endocrinol 1992;36:3617.

7 Rieu M, Rosilio M, Richard A, Vannetzel JM, Kuhn JM. Paradoxical effect of somatostatin analogues on the ectopic secretion of corticotropin in two cases of small cell lung carcinoma. Horm Res 1993;39:207-12.

8 Winquist EW, Laskey J, Crump M, Khamsi F, Shepherd FA Ketoconazole in the management of paraneoplastic Cush ing's syndrome secondary to ectopic adrenocorticotropin production. F Clin Oncol 1995;13:157-64.

9 Delisle L, Boyer MJ, Warr D, et al. Ectopic corticotropin syndrome and small-cell carcinoma of the lung: clinical features, outcome, complications. Arch Intern Med 1993;153 $746-52$.

\title{
Chronic leg pain
}

Thrombosis Research Institute, Emmanuel

Kaye Building,

Manresa Road,

London SW3 6LR, UK

S Chang

$T$ Brow

$S \mathrm{~K}$ Das

Correspondence to

Mr S K Das

Accepted 21 January 1998

\author{
Sebastian Chang, Timothy Brow, Saroj K Das
}

A 52-year-old man, on long-term steroids for asthma, presented to neurologists in mid-1993 with a 5-month history of bilateral shin pain. It increased throughout the day, especially on standing and eased at rest. They noted a patch of decreased sensation to pin-prick, temperature and light touch in the left L5 distribution, but electromyography and computed tomography of the lumbar spine showed no nerve impingement. He was investigated by a rheumatology team in October 1993, and because of a previous history of sarcoid lung disease, an isotope bone scan was arranged, which was normal. He was seen by an orthopaedic team in 1994 and magnetic resonance imaging showed "moderate sized L5/S1 disc protrusion, not clinically significant with no evidence of spinal stenosis". Concurrently, he was also investigated by a vascular team; Doppler studies of both limbs were normal, but unfortunately he did not attend a transfemoral angiogram to exclude aorto-iliac disease. He remained symptomatic and was seen by the vascular team again whilst in hospital for respiratory problems in January 1996. Examination revealed a tender anterior compartment and Duplex studies showed no popliteal entrapment. The compartment pressure readings are shown in the table. Ankle brachial index measurements were 0.9 (right side) and 0.89 (left side).

A diagnosis of chronic compartment syndrome was made. He underwent a bilateral extensor and peroneal compartments fasciotomy (closed technique) in April 1996. In September 1996 his right leg remained pain free but his left leg symptoms returned. Repeated compartment pressure readings were taken (table). A transfemoral angiogram showed adequate flow in both limbs and ankle brachial index readings were 1.1 bilaterally.

Table Intracompartmental resting pressure readings (mmHg)

\begin{tabular}{llllll}
\hline & \multicolumn{2}{l}{$\begin{array}{l}\text { Pre-fasciotomy } \\
\text { (April 1996) }\end{array}$} & & \multicolumn{2}{l}{$\begin{array}{l}\text { Post-fasciotomy } \\
\text { (Sep 1996) }\end{array}$} \\
\cline { 2 - 3 } \cline { 5 - 6 } & Right & Left & & Right & Left \\
\hline Extensor & 33 & 30 & & 15 & 15 \\
Peroneal & 15 & 24 & & 12 & 18 \\
Flexor & 15 & 19 & & 12 & 18 \\
\hline
\end{tabular}

\section{Questions}

1 What is the differential diagnosis of chronic leg pain?

2 What are the clinical features of compartment syndrome?

3 How should this diagnosis be confirmed?

4 What would the next stage of management be? 